\title{
Exploring China's Role in the Global Economy: Financial Crisis, Adjustment, and Global Prosperity*
}

\author{
Linyue Li \\ Central University of Finance and Economics, Beijing, China
}

\begin{abstract}
The purpose of this paper is to update China's economic role in the global economy, under the background of the global financial crisis and the rising impact of emerging Asian economies, by investigating the evolution and the nature of macroeconomic interdependence between China and other major players in the world economy, such as other emerging Asia and major industrial countries. To discuss China's economic relationship with other emerging Asian countries and with major industrial countries, such as G7, changes in inter-regional and intra-regional economic linkages of trade and financial markets through various business cycle co-movements between emerging Asia and major industrial countries (G7 economies) are reviewed in the existing literature. Since it would be interesting to investigate the direction and magnitude of growth spillovers and business cycle synchronization between China and other major players in the world economy, a four-variable Vector Auto-Regression (VAR) model is employed to assess the evolution of macroeconomic interdependence and to measure bi-directional macroeconomic impacts between China and other major players in the global economy. Country specific models for Hong Kong, South Korea, Thailand, Japan, and the United States are analyzed. The question on how China will contribute to battling the crisis and continue to play a crucial role in stabilizing the future world economy is the main focus. This paper provides some thoughts for further study of China's role in the global economy.
\end{abstract}

Keywords: China's role, global aggregate, regional aggregate, financial crisis

As the influence of emerging market economies such as Brazil, Russia, India, and China (BRICs) ${ }^{1}$ increases in the world economy, under the background of global financial crisis, China as the center of Asia emerging economies has caught most of the concerns in the world. In 2010, China has passed Japan to become the second largest economy in the world (Bogaisky, 2011) and has replaced Germany to become the largest exporter and the second largest importer of goods in the world economy (Central Intelligence Agency [CIA], 2012). China's growing role as an engine of growth for Asian and the world economy has highlighted China's importance in East Asia's recovery from the recent global financial crisis. There is little doubt that China is already a major driver of the global growth, as the engine of the global economy, mainly due to the great

\footnotetext{
* This paper is supported by National Natural Science Foundation of China (NSFC).

Corresponding author: Linyue Li, Ph.D. in Economics, assistant professor, School of International Trade and Economics, Central University of Finance and Economics, Beijing, China; research fields: international economics, international money and finance, international trade, and applied econometrics.

1 The acronym of BRIC, coined by Jim O'Neill in a 2001 paper entitled "Building Better Global Economic BRICs", has come into widespread use as a symbol of the shift in global economic power away from the developed G7 economies towards the developing world. Do not confuse with BRICS (Brazil, Russia, India, China, and South Africa), distinguished by their large economies and significant influence on regional and global affairs.
} 
potential of consumption and the amazing speed of technology spread through the transition from "Made in China" to "Created in China". Therefore, it is only a matter of time for China to regain ${ }^{2}$ its powerful position in the world economy.

From 1980 to 2011, the share of China's GDP (Gross Domestic Product) in the world economy has increased from $2.19 \%$ to $14.35 \%$, valued at purchasing power parity basis, and it will keep the trend to approach 20\% in 2016, projected by IMF staff (International Monetary Fund [IMF], 2012a). When valued at market exchange rates, the share of China's GDP in the world economy is $9.5 \%$ in 2010 and $9.2 \%$ in 2011 (International Monetary Fund [IMF], 2012b), still much higher than most of the major economies, such as the United States, Euro area, and Japan. The huge difference between the value at purchasing power parity basis and the value at market exchange rates is due to the difference between the prices of traded and non-traded goods that leads to an understatement of the real incomes of most developing countries and an exchange rate that it is widely, although not universally, viewed as being substantially undervalued (Zhang, Willett, \& Li, 2011). The economy of BRICs has accounted for about $2 / 3$ of the world's economic growth in recent years, and China's contribution to the world growth is above $25 \%$ in 2011, at purchasing power parity basis. Interestingly, when the negative lag effects from global financial crisis hit and then lingered around the world in 2009, the absolute value of China's GDP growth still keeps high at 852.168 units $^{3}$, while that of world's GDP growth shrinks to 68.411 units. Although the increased value of China's GDP growth is lower than the previous years, it is over 12 times than that of the world's GDP growth in 2009, indicating China's role in helping other countries, such as emerging Asian and major industrial countries, and reducing negative effects from global financial crisis through trade and financial channels. The huge negative GDP growth from G7 drags down the world GDP growth to a low level by offsetting the big positive growth contribution from China, other emerging Asia, and India. China's increased proportion of the contribution to the world GDP growth appears dramatic from the decade of 1990-2000 to the decade of 2000-2010 (see Figure 1).

While China maintains relatively high economic growth rate in the global crisis, the decoupling of China may not be as great as many popular analyses have suggested (Zhang et al., 2011). On the one hand, due to the heavy reliance of trade on the Euro area and the United States, China's economic growth rate would drop abruptly if the Euro area experiences a sharp recession threatening the global recovery (International Monetary Fund [IMF], 2011b), although China's exports have lowered consumer prices across the globe and its imports have begun to have a major impact on global commodity prices (Zhang et al., 2011). On the other hand, in the aspect of financial spillovers, global financial market co-movement has increased significantly in recent years. The stock market correlations between China and the United States rose sharply in the past few years, but they were low before the mid-2000s.

At the regional level, the rise in regional stock market co-movements with respect to China in recent years can be illustrated by the increasing average of country pair stock market correlations among emerging Asian economies (Kim, Lee, \& Park, 2009). However, China's financial market is still quite isolated from the world financial system, while Chinese economy is becoming more integrated with the world economy due to increased trade flows. In fact, this is one of the main reasons that the recent financial crisis has not affected China as much as it does on some other countries (Lien, 2010).

\footnotetext{
${ }^{2}$ China kept ranking number one in the world economy until First Opium War (Britain's invasion of China, 1840-1842). Over one hundred years of economic development through great efforts, China is expected to regain its economic position in the world.

${ }^{3}$ Units measured by Real Gross Domestic Product at $2005=100$.
} 

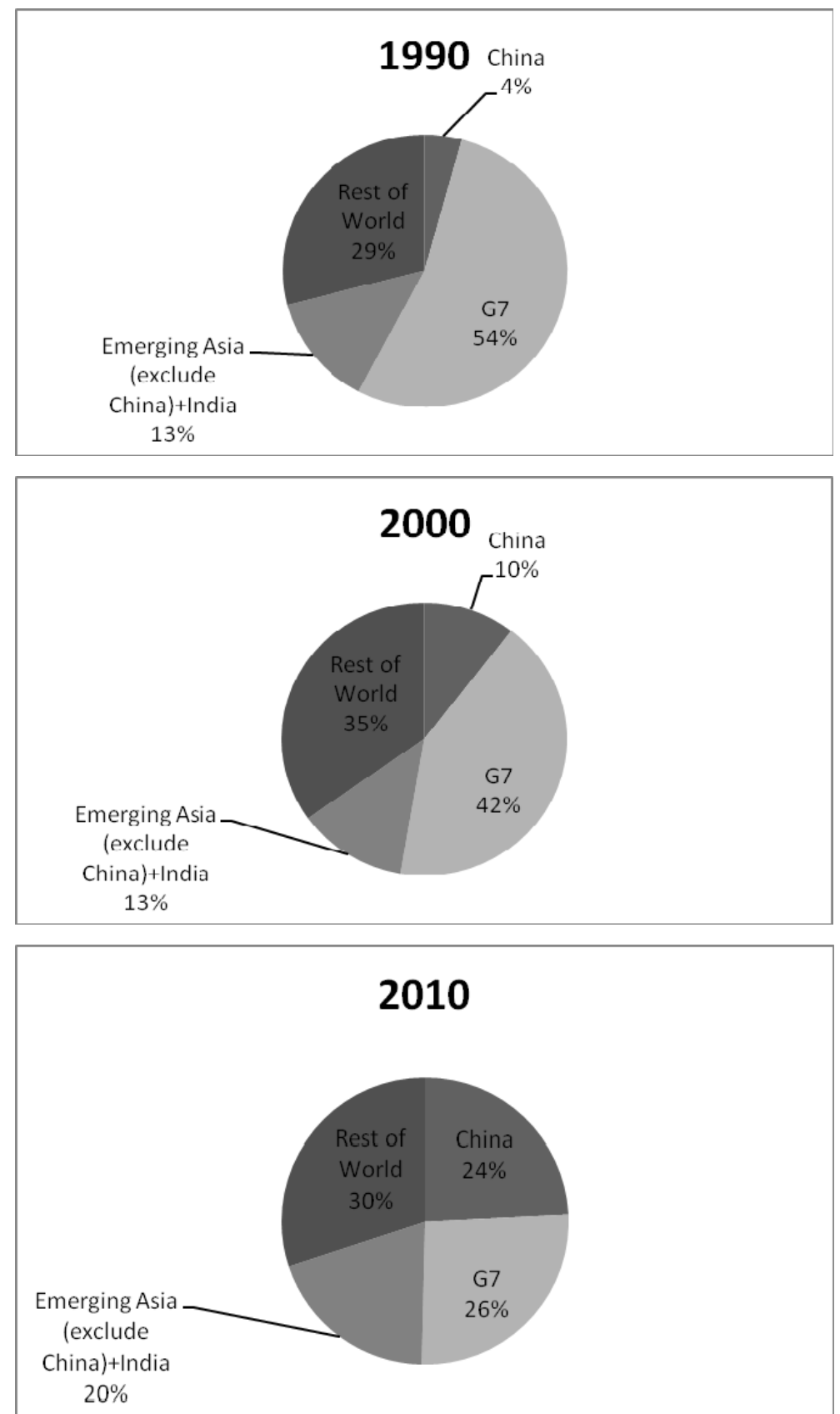

Figure 1. The proportion of world GDP growth. Source: International Monetary Fund's (IMF) World Economic Outlook (WEO) Database.

Notes. Emerging Asia comprises People's Republic of China; Hong Kong, China; Indonesia; Republic of Korea; Malaysia; the Philippines; Singapore; Taiwan, China; and Thailand. India is included due to its impressive growth during recent years. Major advanced economies (G7) include Canada, France, Germany, Italy, Japan, United Kingdom, and United States.

The inspiration of writing this paper is originated from the extension of the decoupling discussion, under the background of global financial crisis and the signs of recovery from the recession. This is some evidence showing that China has helped countries, such as ASEAN (Association of Southeast Asian Nations) in the region to recover swiftly from the global crisis, through strong trade ties. Although Asia's exports to China fell 
dramatically during the crisis, the exports to China rebounded more strongly than exports to the United States, therefore helping support growth (Estrada, D. H. Park, I. W. Park, \& S. C. Park, 2012). It is meaningful to update China's role in the global economy to further discuss how China should play its important role in battling the financial crisis and moving forward for continued and sustainable global economic prosperity, facing the tough challenges and great opportunities in the world economy.

\section{Literature Review}

Existing literature working on China's role in the global economy usually starts with investigating the evolution of business cycle co-movement between China and its major trading partners, such as the United States, Japan, and other emerging Asian countries. During global financial crisis, the performance of emerging Asia, especially China, has shaken the role of the United States, as the locomotive of the world economy, therefore, decoupling debate becomes popular again (Li, 2011). The popular hypothesis of decoupling indicates the idea that strengthening regional ties among emerging Asian economies through growing intra-regional trade, investment, and financial linkages might help emerging Asia relieve the negative shocks from other major industrial countries.

The analytical results from empirical studies or comparative studies differ on the extent and nature of business cycle co-movement between China and its major trading partners, due to the choice of sample periods and empirical methodologies. Although the results from existing literature vary, most of the empirical studies find that the degree of business cycle synchronization among Asian economies has been increasing, mainly due to deepened trade integration and financial linkages. However, it is not conclusive whether the output of Asian economy has been decoupled from, or become less interdependent with, the global economy (Kim et al., 2009).

Based on standard correlation approach, the correlation coefficients of business cycles among emerging Asian economies and with G3 (Japan, the United States, and the European Union) increased and remained high after the 1997-1998 Asian financial crises. The high synchronicity of business cycle correlation between Asia and the G3 is interpreted as evidence supporting recoupling view of Asian economies with major industrial countries, rather than decoupling (Kim et al., 2009). However, the static correlation approach is likely to generate highly unstable results without distinguishing regional shocks from global shocks (Asian Development Bank [ADB], 2009).

Considering the disadvantages of conventional correlation approach in discussing the issue of decoupling, dynamic factor models are employed to complement. Several studies decompose an economy's output into components by different factors, such as global factors, regional factors, and country specific factors. Moneta and Ruffer (2006) found a significant common factor in the business cycles of 10 (ten) East Asian economies by using a dynamic factor model for their output; specifically, a considerable part of the common factor comes from the co-movement in exports, which is generated from exogenous factors such as oil price and exchange rate of Japanese yen in terms of US dollar. Kose, Otrok, and Prasad (2008) discovered that the generated global factors and group specific factors (or regional factors) have accounted for a sizable proportion of business cycle fluctuations in both industrial countries and emerging market economies which include emerging Asian economies, however, the relative importance of the global factors decreased, at the same time, the importance of group specific factors (or regional factors) increased. The results of Kose et al.'s framework suggest that the theory of decoupling holds between the groups of industrialized countries and emerging Asian economies, while there exists recoupling of business cycles among the two groups. 
Li (2011) used both correlation approach and dynamic factor models to study the evolution of global business cycle linkages to let these two approaches implement each other. China's special role in trade transmission is illustrated through comparative studies with other Asian economies, such as Thailand, Japan, South Korea, and Malaysia. The results cast doubt on the strong forms of both the decoupling and the recoupling hypotheses. However, it is confirmed in many empirical studies that the influence from common regional shocks has increased after the 1997-1998 Asian financial crisis.

Vector Auto-Regressive (VAR) approach is also applied by several studies to distinguish the nature of shocks and analyze the output interdependence for East Asia. Kim and Lee (2008) and Takagi and Kozuri (2008) also found that Asia's output linkage increased significantly after 1997-1998 Asian financial crisis, regionally and globally. Kim et al. (2009) also employed a panel VAR model to study the relationship between global economy and Asian regional economies, and their effects on the individual economy of individual Asian economies, especially the relationship between China and other emerging Asian economies. At first, they document the trends and stylized facts about Asian business cycles by using correlation statistics and find that, consistent with previous studies, Asian's output is responding significantly to both regional and global output shocks after 1997-1998 Asian crisis, in addition, Asian business cycles have become much more stable after 1997-1998 Asian crisis, although they still exhibit higher volatility than major industrial economies, such as G7. They discover a notable exception of the behavior of post-crisis Asian business cycles, that is, China's economy appears to beat the business cycle of G7 and other emerging Asian economies with continued robust growth regardless of the ups and downs of the regional and international economy, while the patterns of other emerging Asian economies' business cycles were becoming more synchronized with that of G7, in terms of upturns and downturns.

As the impact of emerging Asia rises, especially China, the direction and magnitude of trade and financial flows which are considered as important factors for macroeconomic interdependence are changing rapidly. To examine the effect of growing Asian influence on the global business cycle, Kim et al. (2009) applied a three-variable panel VAR model to identify the relevant structural shocks, such as global and regional shocks and then analyzed the effects of each shock on an individual variable in a systematic way. They find that the effects of Chinese and other emerging Asian economies on the global economy also increased in post-crisis period, while the effects of global shocks on emerging Asian, and especially Chinese economy increased substantially. Therefore, the uni-directional dependence to explain the macroeconomic relationship between developing and developed countries will be replaced by the thought of bi-directional dependence. To further explore the nature of macroeconomic interdependence between China and other emerging Asian countries, between China and global effects from major industrial economies, the author extends Kim et al.'s VAR model to four-variable VAR and analyzes China's effect on the specific country to examine the role of China's economy.

\section{Estimation Framework and Analysis}

Real GDP in units $(2005=100)$ is applied as the measure of output. Nine emerging economy countries including China (Mainland), Hong Kong, South Korea, Indonesia, Malaysia, the Philippines, Singapore, Thailand, and Taiwan, are selected because they are widely discussed in other empirical studies and they often lead to conflicting results. The world aggregate is constructed by using the aggregate of G7's real GDP. G7 countries consist of Canada, France, Germany, Japan, Italy, United States, and United Kingdom. In terms of sample period, data availability for most of the countries determines the starting and the end points (see Table 1). 
Table 1

Data Description and Sources

\begin{tabular}{lllll}
\hline Symbol & Description & Sources & Frequency & Period \\
\hline RY_CHN & China's GDP & IFS & Quarterly & $1988 \mathrm{q} 1-2011 \mathrm{q} 2$ \\
RY_HKG & Hong Kong's GDP & IFS & Quarterly & $1988 \mathrm{q} 1-2011 \mathrm{q} 2$ \\
RY_IND & Indonesia's GDP & IFS & Quarterly & $1988 \mathrm{q} 1-2011 \mathrm{q} 2$ \\
RY_KOR & Korea's GDP & IFS & Quarterly & $1988 \mathrm{q} 1-2011 \mathrm{q} 2$ \\
RY_MLS & Malaysia's GDP & IFS & Quarterly & $1988 \mathrm{q} 1-2011 \mathrm{q} 2$ \\
RY_PHL & Philippines' GDP & IFS & Quarterly & $1988 \mathrm{q} 1-2011 \mathrm{q} 2$ \\
RY_SGP & Singapore's GDP & IFS & Quarterly & $1988 \mathrm{q} 1-2011 \mathrm{q} 2$ \\
RY_THL & Thailand's GDP & IFS & Quarterly & $1988 \mathrm{q} 1-2011 \mathrm{q} 2$ \\
RY_TWN & Taiwan's GDP & IFS & Quarterly & $1988 \mathrm{q} 1-2011 \mathrm{q} 2$ \\
GY_A9 & Asian aggregate & IFS & Quarterly & $1988 \mathrm{q} 1-2011 \mathrm{q} 2$ \\
GY_AXC & Asian aggregate excluding China & IFS & Quarterly & $1988 \mathrm{q} 1-2011 \mathrm{q} 2$ \\
GY_7 & World aggregate & IFS & Quarterly & $1988 \mathrm{q} 1-2011 \mathrm{q} 2$ \\
GY_6 & World aggregate excluding Japan & IFS & Quarterly & $1988 \mathrm{q} 1-2011 \mathrm{q} 2$ \\
US & The United States' GDP & IFS & Quarterly & $1988 \mathrm{q} 1-2011 \mathrm{q} 2$ \\
\hline
\end{tabular}

Empirical estimation model is constructed through a four-variable VAR model \{GY_7, GY_A9, RY_CHN, and RY_i\}, RY_i stands for one of countries in the system, excluding China. The relationship between China and one of the five countries (Hong Kong, South Korea, Thailand, Japan, and the United States) is mainly focused on. The model will be estimated for two sample periods: 1988q1-1996q4 and the whole period 1988q1-2011q2. Two lags and a constant term are assumed to fit the model. In the four-variable estimation frameworks, the contemporaneously exogenous variables, such as GY_7, are ordered first. The variables, such as GY_7, GY_A9, and RY_CHN are included to examine the relationship of the effects from the global, Asian aggregate, and China's shocks. The world aggregate constructed by the aggregate of G7 is treated as contemporaneously exogenous to Asian regional aggregate output, China's real output and individual country's output, while Asian regional aggregate output is treated as contemporaneously exogenous to China's real output and individual country output.

In the impulse responses (IR) and the related forecast error variance decomposition (FEVD) of the model $\left\{G Y \_7, G Y \_A 9, R Y \_C H N\right.$, and RY_HKG $\}$ for 36 quarters in pre-crisis period and the whole period, the shock is based on one standard deviation and $90 \%$ probability bands are denoted by dotted lines for the graphs of impulse response function. The graphs in one column show the responses of the four different variables to the one standard deviation shock from the same variable, while the graphs in one row show the responses of the same variable to the one standard deviation shocks from four different variables.

The IR illustrate that the effects of global shocks (denoted by GY_7) on the Asian aggregate, China's real GDP, and HKG's real GDP increased from approximately 0 to the range of $2 \%-10 \%$ and the effects are more persistent, when comparing the pre-crisis period with the whole period. The effects from China's shocks become much larger in the whole period, comparing with the pre-crisis sub-period (see Figure 2). Furthermore, the responses of global factors $\left(\mathrm{GY}_{-} 7\right)$ and the responses of aggregate Asia (GY_A9) to the shock from China (RY_CHN) become positive in the whole estimation period from negative in the pre-crisis period, indicating the increasing influence of China on regional and global economies. In terms of China's real output responses to the four different variables, the responses become dramatically larger in the whole period than in the 
pre-crisis period. Therefore, in the model of $\left\{\mathrm{GY} \_7, \mathrm{GY} \_\mathrm{A} 9, \mathrm{RY}\right.$ CHN, and RY_HKG $\}$, the effects of China's shock and the response of China are bi-directional, like a pair of action and reaction in physics.

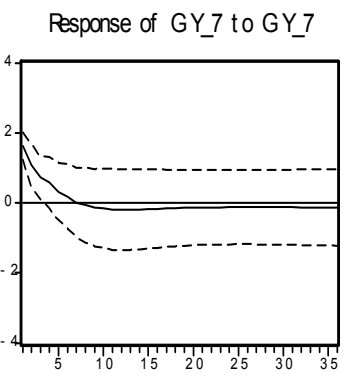

Response of GY_A9 to GY_7

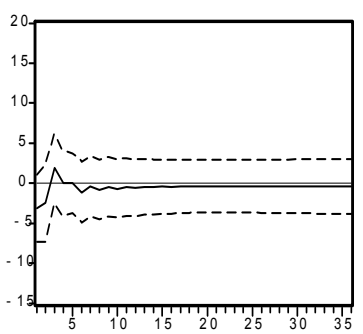

Response of RY_CH to GY 7

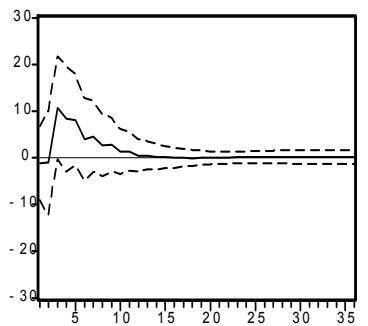

Response of RY_HK to GY 7

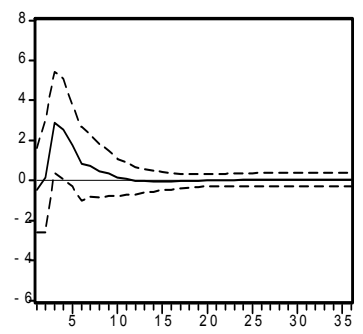

Response of GY7 to GY_A9

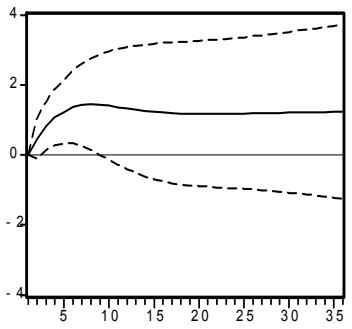

Response of GYA9 to GYA9

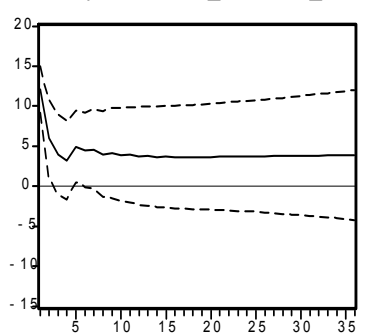

Response of RY_AN to GY_A9

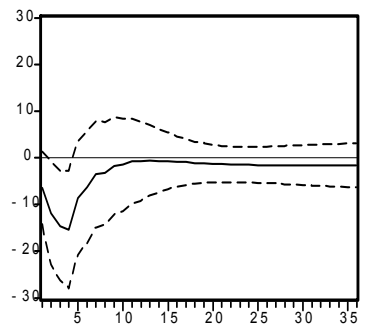

Response of RYHK to GYA9

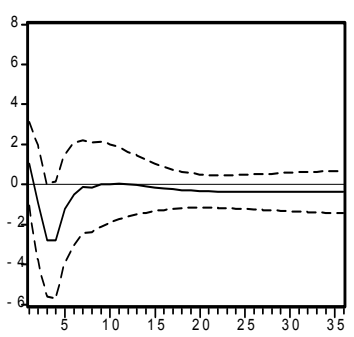

Response of GY 7 to RY_AH

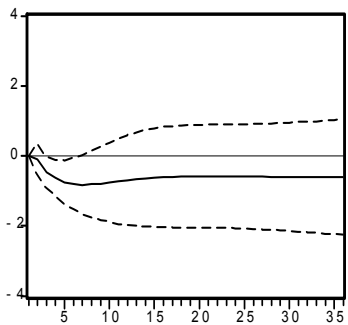

Response of GYA9 to RY_CH

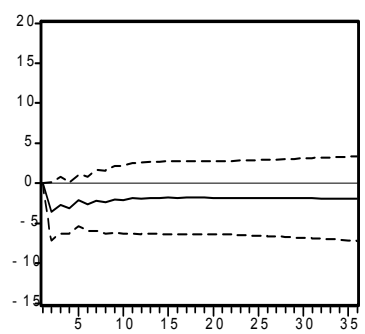

Response of RY_CH to RY_OH

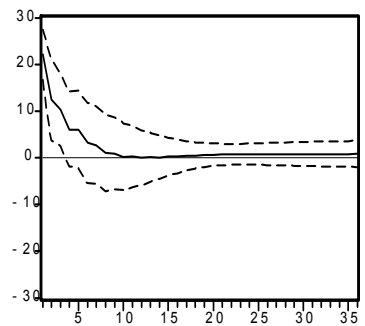

Response of RYHKG to RY OHN

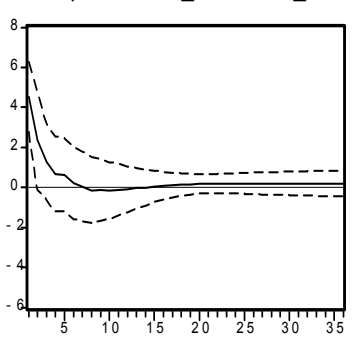

Response of GY_7 to RY_HG

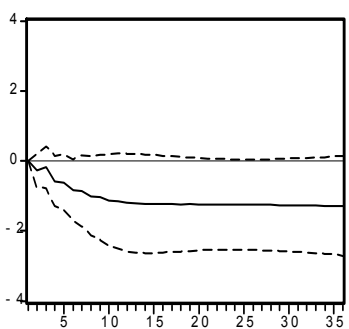

Response of GYA9 to RY HKG

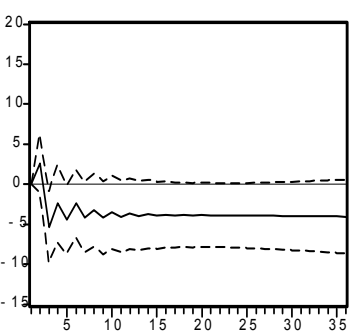

Response of RY_AN to RY_KG

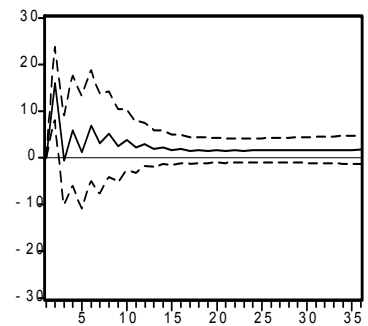

Response of RY_HG to RY_KG

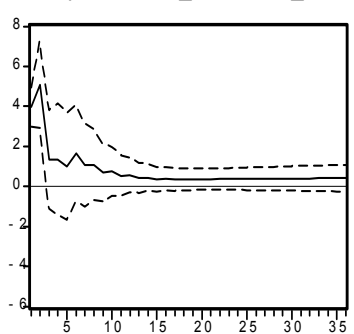

Figure 2. Impulse Response Function (IRF). IR of (GY_7, GY_A9, RY_CHN, and RY_HKG) to one s.d. shock of each other, 1988Q1-1996Q4.

To decipher the role of different shocks in explaining output fluctuations, FEVD is applied. The results from FEVD are reported in Figure 3. The portion of Hong Kong's real output fluctuation explained by China increases from $25 \%$ to about $42 \%$, and the portion of GY_7 real GDP fluctuations explained by China also increases from less than $20 \%$ to more than $20 \%$, when post-crisis period is added in the estimation period. Comparing with the pre-crisis period, China's real output fluctuations explained by itself go up from about $40 \%$ to $70 \%$, while the portions explained by other variables (GY_7, GY_A9, and RY_HKG) decrease. 

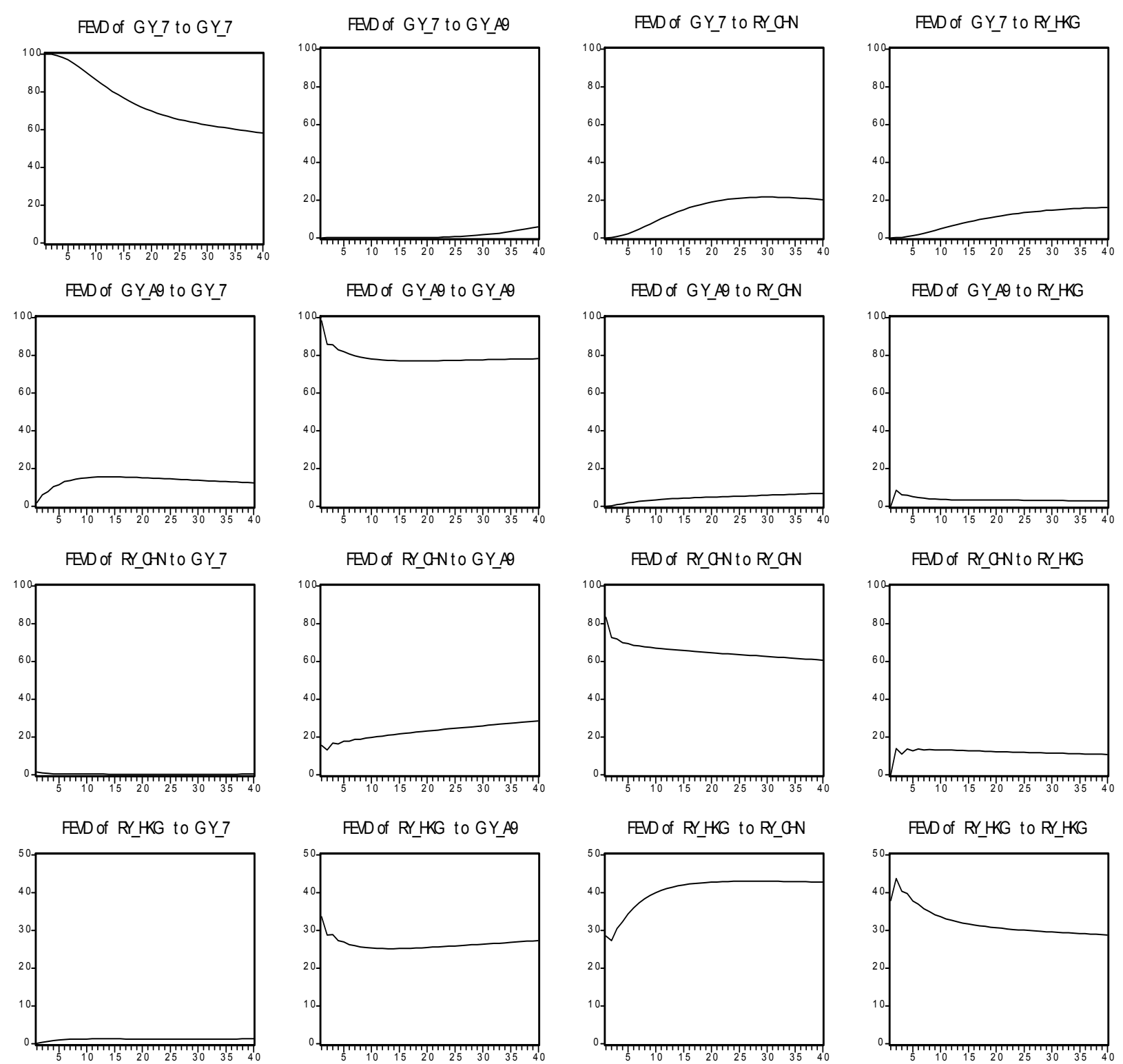

Figure 3. Forecast Error Variance Decomposition (FEVD) (\%). FEVD of (GY_7, GY_A9, RY_CHN, and RY_HKG) to one s.d. shock of each other, 1988Q1-2011Q2.

Similarly, in the IR and the related FEVD of the model \{GY_7, GY_A9, RY_CHN, and RY_KOR\} for 36 quarters in pre-crisis period and the whole period, on the whole, the responses of the four different variables (GY_7, GY_A9, RY_CHN, and RY_KOR) to the one standard deviation shock from China increase with wider bands, when the post-crisis period is added in the whole estimation period. However, the four different variables explained by China shocks and the portion of China's output fluctuations explained by the four different variables decrease in the whole estimation period, except for the proportion of Korea's output fluctuations explained by China's shocks.

In the IR and the related FEVD of the model $\left\{G_{-}\right.$7, GY_A9, RY_CHN, and RY_THL $\}$for 36 quarters in pre-crisis period and the whole period, similar to the model $\{\mathrm{GY}$ 7, GY_A9, RY_CHN, and RY_KOR $\}$, in 
the whole period, the effects of the global shocks, Asian aggregate shocks, and China's shocks increase with wider bands, comparing with the pre-crisis period. In general, the size and the persistence of the effects of global shocks, Asian aggregate shocks, and China's shocks can be ranked as the effect of Asian aggregate $>$ the effect of global shocks $>$ the effect of China's shock (GY_A9 > GY_7 > RY_CHN), in the model \{GY_7, GY_A9, RY_CHN, and RY_THL\}. In terms of FEVD, the proportions of output fluctuations explained by China's shocks increase, except for the case of aggregate Asian output, at the same time, the proportions of China's output fluctuations explained by aggregate Asian shocks, the global shocks, and Thailand's shocks decrease from the pre-crisis period to the whole period.

In the IR and the related FEVD of the model $\{\mathrm{GY}$ 7, GY_A9, RY_CHN, and RY_US $\}$ for 36 quarters in pre-crisis period and the whole period, different from the previous cases that one of the emerging Asian economies is included as the fourth variable in VAR, the IR of the four variables to China's shocks decrease in the whole period, while the IR of the four variables to US's shocks increase from negative to positive, comparing with the pre-crisis period. One thing consistent with the previous cases is that the effects of Asian aggregate shocks still keep larger than that of the global shocks, when one of the emerging Asian economies is included as the fourth variable in the model, instead of US's real GDP. With respect to the results from FEVD, the proportions of the four different variables explained by China's shocks decrease and correspondingly the proportions of China's fluctuations explained by variables decrease, except for the proportion of China's output fluctuations explained by Asian aggregate shocks. The proportions of the output fluctuations for global output fluctuations, Asian aggregate output fluctuations, and US's own output fluctuations explained by US's shocks increase, however, only the proportions of China's output fluctuations explained by US's shocks decrease from $15 \%$ to $3 \%$. In addition, the proportions of Asian aggregate output fluctuations explained by the shocks from its own shocks increase from $30 \%$ to $80 \%$, indicating the rising impact of Asian regional integration.

In the IR and the related FEVD of the model $\left\{\mathrm{GY} \_6, \mathrm{GY} \_\mathrm{A} 9, \mathrm{RY}\right.$ CHN, and RY_JPN\} for 36 quarters in pre-crisis period and the whole period, since Japan is the only industrial country in Asia, GY_7 is replaced by GY_6 as the global aggregate output in order to examine the effects from other major industrial countries (non-Asian countries). The effects of China's shocks on the other variables decrease, from positive to negative, in the whole period, when comparing with the pre-crisis period. Coincidently, the responses of the four different variables to the shocks of Japan also decrease from positive to negative. However, the response of China's output fluctuations increases to the shocks from Asian aggregate, while the response of China's output fluctuations to the shocks from other variables decreases from pre-crisis period to the whole period. Consistent with the previous models, the effects of Asian aggregate are much larger and persistent with wider bands than that of global aggregate constructed by GY_6 excluding Japan, which could confirm the increasing impact of emerging Asia, comparing with the effects of major industrial countries (GY_6).

In terms of the results from FEVD, the proportion of global aggregate (GY_6) fluctuations explained by its own shocks increases from $30 \%$ to $80 \%$ and the proportion of aggregate Asia (GY_A9) fluctuations explained by its own shocks also increases with different magnitude, from $40 \%$ to $85 \%$, while the proportions of China's output fluctuations and Japan's output fluctuations explained by their own shocks decrease from $60 \%$ to $8 \%$ for China and from $28 \%$ to $20 \%$ for Japan. In addition, China's output fluctuations explained by Asian aggregate shocks increase from $5 \%$ to $90 \%$, indicating the increasing integration between China and other emerging Asian economies mainly through trade and financial transmissions. 


\section{Conclusions and Implications for China}

As the share of emerging Asian economy continues to increase in the global economy through trade and financial linkages, the influence from emerging Asian economies, especially China, becomes much greater in the global market. The behavior patterns of impulse response effects between emerging Asia (GY_A9) and the global aggregate (GY_7 or GY_6), between China and global aggregate, are expected to have stronger action and reaction effects (bi-direction).

Related evidence can be found in the model with Hong Kong, the model with South Korea, and the model with Thailand. On the whole, the responses of other variables to China's shocks increase when post-crisis and the latest data are added in the estimation models with one of the emerging Asian countries, such as Hong Kong, South Korea, and Thailand. In the model with Thailand, the proportions of global, Asian regional, and Thailand's output fluctuations explained by China's shocks increase, indicating China's rising impact in emerging economies, such as Thailand. But, in different model with different emerging Asian countries, the direction and dynamics from China's effects are quite different. Therefore, it is necessary to specify the model for individual country and relate China's effects to the effects from global aggregate and Asian aggregate, when considering the dynamics of China's shocks to different countries.

One consistent result in the five different models (model with Hong Kong, model with South Korea, model with Thailand, model with US, and model with Japan) is that the effects of Asian aggregate are much larger and more persistent than the effects of global aggregate (GY_7 or GY_6), indicating the increasing impact of emerging Asia, comparing with the impact from major industrial economies. As the shocks from emerging Asia economies have a greater positive influence on global economies than the effects of global economies on emerging Asia, the emerging Asia is expected to have increasing impact and important role in global economy. In the world market of primary commodities, driven by rapid income growth and demand for economic development, China, as the hub of intra-industry trade in emerging Asia and the manufacturing factory in the global economy, has surfaced as the major source in determining the price dynamics of primary commodities. Through tightening intra- and inter-industry trade linkages intra-regionally and inter-regionally, combining with the increasing globalization of financial markets, China is making fundamental influence to the nature of macroeconomic interdependence and growth spillovers between emerging Asia and the major industrial countries, such as $\mathrm{G} 7$.

The growing influence of China and other Asia countries necessitates an amplification of Asia's voice to be heard in global forums and institutes, especially as China is having an increasingly large impact on the global economy, although the economic interdependence through shocks and the responses runs strongly bi-directionally. Chinese government is able to control China's economy by taking forceful policy actions to reduce the negative effects of the global recession, under the condition of increasing exposure to the world economy through increasing exports and imports. However, facing complicated international economic environment, especially the storm emanating from Europe and the United States, China needs to rebalance its economy for sustainable economic growth and play an important role in promoting the global recovery.

\section{References}

Asian Development Bank (ADB). (2009). Emerging Asian regionalism: A partnership for shared prosperity. Manila: Asian Development Bank. 
Bogaisky, J. (2011). China passes Japan to become world's No. 2 economy, probably. Forbes. Retrieved from http://www. forbes.com/sites/jeremybogaisky/2011/02/13/china-passes-japan-to-become-worlds-no-2-economy-probably

Central Intelligence Agency (CIA). (2011). The World Fact Book: China's economy. Retrieved from https://www.cia.gov/ library/publications/the-world-factbook/ geos/ch.html

Central Intelligence Agency (CIA). (2012). The World Fact Book. Retrieved from https://www.cia.gov/library/publications/theworld-factbook/index.html

Estrada, G., Park, D. H., Park, I. W., \& Park, S. C. (2012). The PRC's Free Trade Agreements with ASEAN, Japan and the Republic of Korea: A comparative analysis. Asian Development Bank Working Paper Series on Regional Economic Integration.

Huh, C.-G., \& Kim, C.-B. (2011). Economic crises, export growth and macroeconomic changes: Has Korea's economy become more vulnerable to external shocks? Conference Paper for Korea and the World Economy X.

International Monetary Fund (IMF). (2012a). World Economic Outlook. Retrieved from http://www.imf.org/external/pubs/ft/weo/ 2011/02/weodata/index.aspx

International Monetary Fund (IMF). (2012b). China Economic Outlook. Prepared by the IMF Resident Representative Office, People's Republic of China, International Monetary Fund.

Kim, S. Y., \& Lee, J.-W. (2008). Real and financial integration in East Asia. ADB Working Paper Series on Regional Economic Integration No. 17.

Kim, S. Y., Lee, J.-W., \& Park, C.-Y. (2009). Emerging Asia: Decoupling or recoupling. Asian Development Bank Working Paper Series on Regional Economic Integration.

Kose, M. A., Otrok, C., \& Prasad, E. (2008). Global business cycles: Convergeance or decoupling? International Monetary Fund Working Paper No. 08/143.

Li, L. Y. (2011). Convergence or decoupling in East Asia through trade transmission: An empirical study by using standard correlation approaches and dynamic factor models. Germany: LAP Lambert Academic Publishing.

Li, L. Y., Zhang, N., \& Willett, T. D. (2011). Measuring macroeconomic and financial market interdependence: A critique survey. Journal of Financial Economic Policy, 4(2), 128-145.

Lien, D. (2010). Recent development in China's financial markets: An introduction. International Review of Economics and Finance, 19(2010), 177-179.

Moneta, F., \& Ruffer, R. (2006). Business cycle synchronization in East Asia. European Central Bank Working Paper No. 671.

Takagi, S., \& Kozuru, I. (2008). Output and price linkages in Asia's post-crisis macroeconomic interdependence. Nanyang Technological University.

Zhang, N., Willett, T. D., \& Li, L. Y. (2011). The effects of the global financial crisis on China's financial market and macroeconomy. The special issue "China after the Global Financial Crisis" published in Economic Research International, Volume 2012, Article ID 961694, Hindawi Publishing Corporation. 